\title{
Improving Oil Products Quality by Vermiculite Sorbent
}

\section{KULASH K. SYRMANOVA ${ }^{1,2 *}$, ZHANAT B. KALDYBEKOVA ${ }^{1}$, NURZHAN Y. BOTABAYEV ${ }^{1}$, YERSULTAN T. BOTASHEV ${ }^{1}$, MOLDIR T. SULEIMENOVA ${ }^{2}$, BORIS Y. BELOBORODOV ${ }^{1}$ and TATYANA V. RIVKINA ${ }^{1}$}

\author{
${ }^{1}$ Auezov South Kazakhstan State University, Kazakhstan, 160012, Shymkent, \\ Tauke Khan av., 5, Kazakhstan. \\ 2"MIRAS" University, Kazakhstan, 160012, Shymkent, llyaev st., 5, Kazakhstan. \\ ${ }^{3}$ Gubkin Russian State University of Oil and Gas, Russian Federation, Moscow, \\ Lenin av., 65, Russia. \\ ${ }^{*}$ Corresponding author E-mail: syrmanova.kulash@mail.ru
}

http://dx.doi.org/10.13005/ojc/340241

(Received: September 13, 2017; Accepted: January 25, 2018)

\begin{abstract}
This article is devoted to the theoretical and experimental research of quality improvement in oil products at adsorptive treatment by vermiculite sorbent. In the conditions of the territorial proximity of sources of sorbents and the importance of improving the quality of various petroleum products, it is actual in the future to create a treatment scheme that includes the stage of adsorption treatment with vermiculite. The purpose of this research on the current stage is the theoretical and experimental justification for qualitative changes in the properties of petroleum products obtained during adsorption treatment. In the course of the research, a complex study of the physico-chemical properties of the vermiculite of the Kulantau field (Kazakhstan) was carried out with reference to petroleum products obtained from high-sulfur low-viscosity oil. The results of the research proved that vermiculites with success can be used to separate any mixtures of molecules, of acceptable size and structure. Also, it can adsorb not only water, but also the products of oxidation of hydrocarbon, oxygen and other heterorganic compounds.
\end{abstract}

Keywords: Adsorbent, Vermiculite, Acid activation, Mineral sorbent, Porization, Porous layer, structure.

\section{INTRODUCTION}

The quality of essential oil products is currently a key issue in the petroleum industry. The problem of quality of petroleum products is closely linked to the conditions of their application and use in engines and machines.
After receiving the plant in the process of storage, transportation and pumping of oil products quality is continuously deteriorating. Light oil products due to incorrect storage are losing the low-boiling fraction, thereby reducing their evaporation in engines. 
During storage and transportation as a result of contact with moist air in the oil gradually accumulates moisture, which degrades the performance properties of fuels and oils. Fuel and oil gradually becomes contaminated with dust from the atmosphere, corrosion products, insoluble substances, resulting from oxidation processes. Therefore, in practice of work of tank farms, warehouses, gas stations, and other organizations and enterprises engaged in the storage and use of petroleum products, have to face with oil products, the quality of which, for whatever reasons deteriorated and does not meet state standards ${ }^{1}$.

Change product quality during storage depends on their chemical composition, conditions of storage, transportation and application of the design features of technical equipment and the condition of their surface in contact with oil. Under the influence of external factors in fuels and oils flow physical and chemical processes. The main physical processes are: evaporation, stratification, contamination of mechanical impurities and water, the deposition of high-melting components during cooling, as well as a random mix of tanks in series pumping through pipelines of petroleum products of different grades, such as jet fuel and gasoline $e^{2,3}$. Most of these processes lead to an irreversible change in the quality of petroleum products. The main chemical processes: oxidation, decomposition, polymerization and condensation, corrosion, interaction between individual components, etc.

\section{MATERIAL AND METHOD}

As an object of research Kumkol oil and petroleum products were used. Physical-chemical characteristics of Kumkol oil are given in Table 1. They were determined by standard methods of determination of oil and oil products properties.

As the adsorbent used Kulantau exfoliated vermiculite. Table 2 shows the physical-chemical properties of Kulantau exfoliated vermiculite ${ }^{4-5}$.

Vermiculites are chemical compounds with variable composition. It could include the following substances: $\mathrm{MgO} 14-15 \%$, FeO 1-3\%, $\mathrm{Fe}_{2} \mathrm{O}_{3} 3-17 \%, \mathrm{Al}_{2} \mathrm{O}_{3} 10-17 \%, \mathrm{SiO}_{2} 34-42 \%, \mathrm{H}_{2} \mathrm{O}$ $8-15 \%$, as well as impurities such as a $\mathrm{Ti}, \mathrm{Ni}, \mathrm{Zn}$, $\mathrm{Cu}, \mathrm{Na}, \mathrm{K}^{6-7}$.
The interlayer and inter-packet intervals vermiculite structure can be regarded as plate micropores having a size of $0.3-1.2 \mathrm{~nm}$. Vermiculite cation exchange capacity is in the range of $100-150 \mathrm{mEq} / 100 \mathrm{~g}$, i.e. clay minerals from it one of the most exchange capable ${ }^{8}$.

Table 1: Physical-chemical characteristics of Kumkol oil

\begin{tabular}{|c|c|c|}
\hline $\begin{array}{l}\text { Characteristic } \\
1\end{array}$ & $\begin{array}{c}\text { Value } \\
2\end{array}$ & $\begin{array}{l}\text { State standard } \\
\text { and methodology } \\
3\end{array}$ \\
\hline $\begin{array}{l}\text { The density at } \\
20^{\circ} \mathrm{C}, \mathrm{kr} / \mathrm{M}^{3}\end{array}$ & 811,7 & $3900-82$ \\
\hline The molecular weight & 230 & \\
\hline $\begin{array}{l}\text { Kinematic viscosity } \\
\text { at } 50^{\circ} \mathrm{C}, \mathrm{MM}^{2} / \mathrm{C}\end{array}$ & 3,53 & $33-82$ \\
\hline $\begin{array}{l}\text { Pour point, }{ }^{\circ} \mathrm{C} \\
\text { processing }\end{array}$ & 6 & 20287-74 \\
\hline $\begin{array}{l}\text { Acid number, } \\
\mathrm{mr} \mathrm{KOH} / 1\end{array}$ & 0,04 & $5985-79$ \\
\hline $\begin{array}{l}\text { Coking ability } \\
\% \text { mass }\end{array}$ & 1,61 & $1933-74$ \\
\hline $\begin{array}{l}\text { Content: \% wt } \\
\text { Asphaltenes }\end{array}$ & 0,3 & \\
\hline Gums silica gel & 6,5 & \\
\hline $\begin{array}{l}\text { Paraffin wax melting } \\
\text { point }{ }^{\circ} \mathrm{C}\end{array}$ & $13,9 / 51$ & $11851-85$ \\
\hline Total sulfur & 0,1 & \\
\hline Total nitrogen & 0,12 & \\
\hline Carbon & 85,74 & \\
\hline
\end{tabular}

Table 2: Physico-chemical properties of exfoliated Kulantau vermiculite

\begin{tabular}{lc}
\hline Poured volumetric mass, $\mathrm{kg} / \mathrm{m}^{3}$ & $80-200$ \\
Coefficient of thermal conductivity & $0,048-0,060$ \\
at $25^{\circ} \mathrm{C}, \mathrm{W} / \mathrm{m}$ grad & \\
The sound absorption coefficient & $0,7-0,8$ \\
$\begin{array}{l}\text { at frequency } 1000 \mathrm{~Hz} \\
\text { Melting point, }{ }^{\circ} \mathrm{C}\end{array}$ & +1250 \\
Application temperature, ${ }^{\circ} \mathrm{C}$ & from -260 \\
& to +1200 \\
\hline
\end{tabular}

\section{RESULTS AND DISCUSSION}

The first step of the research was determination of the degree of purification of gasoline, kerosene, oil, benzene, xylene, toluene, phenol. The results of chromatographic research of initial solutions and the adsorbates are allowed to build the chart given below (Figure. 1-5). 


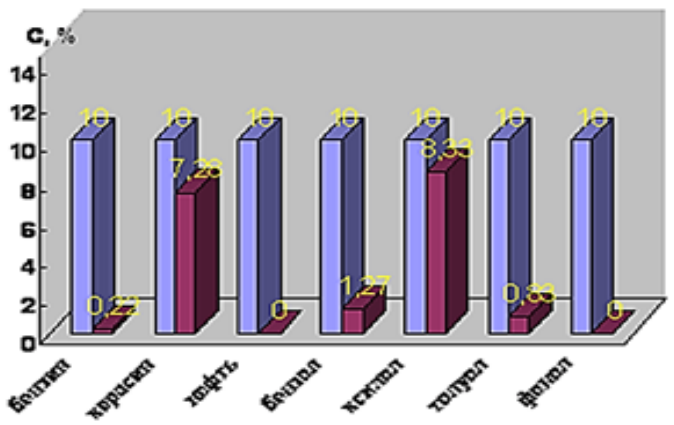

Fig. 1. Changes in the degree of purification of $10 \%$ aqueous $(1: 5)$ solutions of organic substances

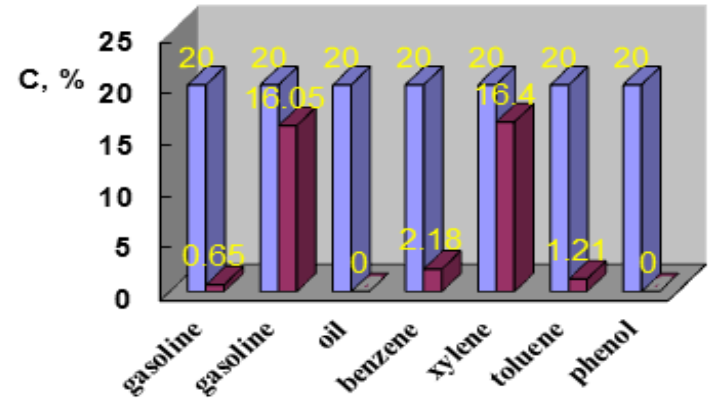

Fig. 2. Diagram changing the degree of cleaning of $20 \%$ aqueous (1:5) solutions of organic substances

C, $\%$

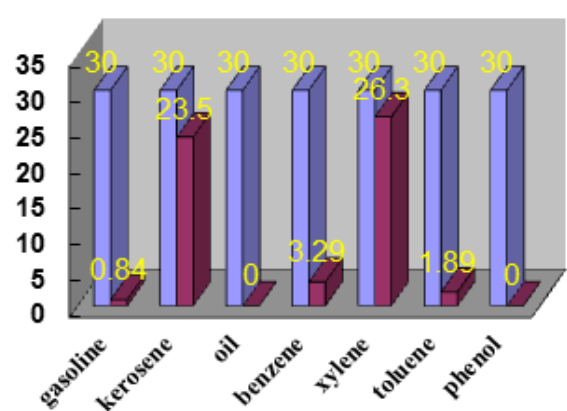

Fig. 3. Changes in the degree of purification of $30 \%$ aqueous (1:5) solutions of organic substances

C, $\%$

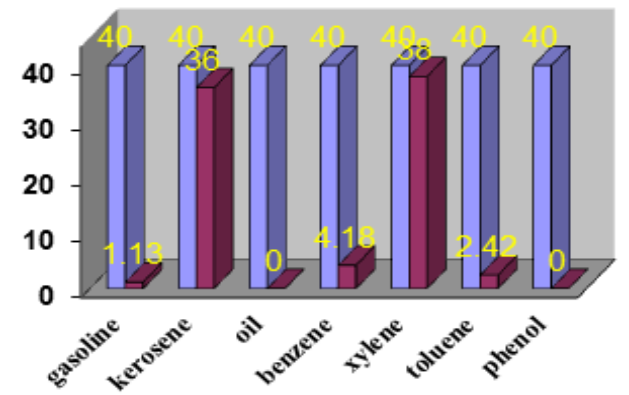

Fig. 4. Changes in the degree of purification of $40 \%$ aqueous (1:5) solutions of organic substances

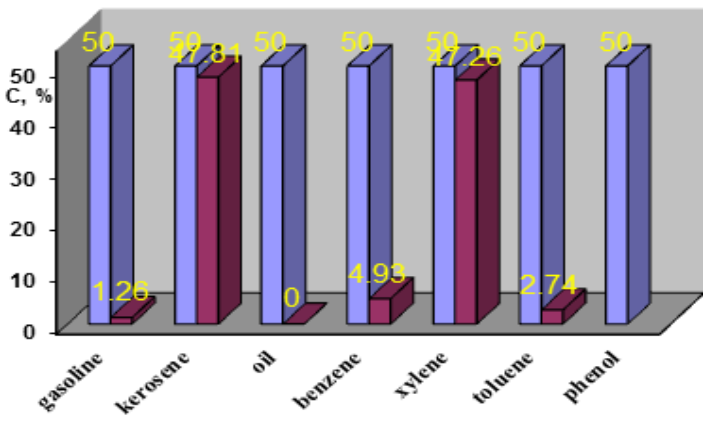

Fig. 5. Changes in the degree of purification of $50 \%$ aqueous (1:5) solutions of organic substances

Accumulated many years of experience in the storage of petroleum products allowed to determine the main quality indicators that have the greatest change during storage and transportation. In Table 3 shown the quality indicators of petroleum products and special fluids, most prone to change in terms of proper storage, in compliance with the rules and regulations. If not properly stored under conditions of leakage, contamination, mechanical impurities and water a number of quality indicators that tend to change increases (Table 4).

Table 3: Change the speed of deposition of particles

\begin{tabular}{lccc}
\hline $\begin{array}{l}\text { The result of distance }(\mu \mathrm{m}) \\
\text { traveled by the particle }\end{array}$ & \multicolumn{3}{c}{ The particle } \\
dhrough the fuel F-1: & 0,1 & 1 & 10 \\
\hline Brownian movement & 10 & 3,1 & 1 \\
Sedimentation & 0,0596 & 5,95 & 596 \\
\hline
\end{tabular}

In light oil the most significantly altered fractional composition. This is due to the relatively low initial boiling point of gasoline and the weak intermolecular interactions of low molecular weight hydrocarbons. In leaded gasoline the content of the tetraethyl lead (TEL) is changing much faster than in a sealed storage, due to low stability of the TEL and its ability to decompose under the action of oxygen and other factors. Under the influence of the oxidation processes in the fuels and oils increases the content of the resins, the acidity, the induction period decreases.

Accelerate the formation of the second phase contribute to pollution mechanical impurities and water, as well as the mix of petroleum products, which differ from each other in chemical composition $^{9}$. The mixture of oil aromatics base with products of alkane base leads to a significant 
increase in the rate of formation of resins and precipitation from solution. Plastic lubricants are most strongly change the dropping temperature, water content, penetration, caused by a change under the influence of external factors of their composition. Some greases contain thickeners, which absorb moisture. In such greases in contact with the atmosphere particularly active increasing the water content. Technical and special liquids of petroleum origin, affected in basically the same change that oil. Their quality is deteriorating, mainly due to oxidation, evaporation and contamination. Alcoholic liquid change the quality mainly due to the absorption of moisture from the atmosphere; alongside it there are, of course, and the oxidation processes, causing acidity, for example, ethyl ether of diethylene glycol and tetrahydrofurfuryl alcohol increases.

Currently, the most real, likely is the addition to clean petroleum products vermiculite ${ }^{10}$. Most real applications of vermiculite is water removal, while the vermiculites. with success can be used to separate any mixtures of molecules, of acceptable size and structure. The vermiculites adsorb not only water, but also the products of oxidation of hydrocarbon resin, oxygen and other heteroorganic connection.

By settling out of fuel, you can remove particles larger than 2-5 microns. In the oil and the fuel oil particles of this size settle very slowly, so slowly that to remove them by settling is practically impossible. Settling effectively from oils and fuel oils to remove particles 50-100 microns. Thus, with increasing viscosity the lower limit (in size) of the removed particles increases.

Particles less than 1 micron from the oil to remove almost impossible. This is because with decreasing size of particles, their mass decreases much faster than the friction force, because the force of gravity for spherical particles is proportional to the third power of particle diameter, and the friction force first. In addition, small particles due to Brownian motion can be easily moved in petroleum, in which there are convection currents caused by temperature difference, vibration, shocks and other causes. As a result, small particles either settle very slowly or do not settle. Changing the particle size one order of magnitude leads to a change in the settling velocity of the particles is two orders of magnitude (Table 5). With decreasing particle diameter the effect of Brownian motion increases.

The deposition rate of particles of natural contaminants strongly depends on the properties of fuels and particle sizes (Fig. 7). Particle size of 30 - 40 microns settle pretty quickly. Gasoline A-72, are deposited almost completely in $1 \mathrm{~h}$, in fuel F-1-per 1.5-2.5 $\mathrm{h}$ and fuel DS- $8 \mathrm{~h}$. Particles of smaller size are deposited at a lower speed. For example, gasoline A-72 particle size of 8-10 $\mu \mathrm{m}$ are deposited halfway through 4-5 h completely - only for $18-20$ hours.

Sedimentation of such particles in the diesel fuel occur many tens of hours. After 4 day they are deposited only on $25-30 \%$. Particle size of 4--7 $\mu \mathrm{m}$ in diesel fuel advocated for more time. Their concentration in the fuel is reduced by half only after 25 days.

After settling, the quantity of contaminants in the secondary fuel sample is reduced to 2.3-2.5 times. Particles larger than $30-40 \mu \mathrm{m}$ are deposited almost completely. Particle size of 15-20 microns are deposited on $40-45 \%$. Much slower to settle finer particles. The sediment at the bottom of tanks over time grow.

Over time, the relative quantity deposited on the bottom of the tanks of small particles decreases and the number of large increases (Table 6). This indicates coagulation of sediment particles flowing at the bottom of the tanks for storage of petroleum products.

Defending impurities from lubricating oils and fuel oils is effective only when $70-90{ }^{\circ} \mathrm{C}$. Increase in temperature above $90{ }^{\circ} \mathrm{C}$ leads to a significant increase in the settling velocity of the particles, which explains the insignificant change of viscosity at temperatures above $90^{\circ} \mathrm{C}$. Increase in temperature above $90{ }^{\circ} \mathrm{C}$ leads to a significant 
increase in the settling velocity of the particles, which explains the insignificant change of viscosity at temperatures above $90^{\circ} \mathrm{C}$. When heated above $100^{\circ} \mathrm{C}$ it is possible to boil water in oil. This process will prevent the deposition of particles. Therefore, the optimal temperature of heating oil should be considered to be $70-90{ }^{\circ} \mathrm{C}$. The efficiency of the settling oil at $80^{\circ} \mathrm{C}$ given in Table 6.

Full deposition of large particles of mechanical impurities in the oil is observed after $18 \mathrm{~h}$ of sedimentation (Table 7). Increase the height of the loading time of settling increases.

However, from the upper layers desilting oil with a high level of loading it is possible to select a pure product with greater speed. Defending oils, especially waste, is not always effective. Even with prolonged settling a considerable amount of dirt remains in suspension. This applies to oils with dispersant additives which prevent settling of finely dispersed contaminants.
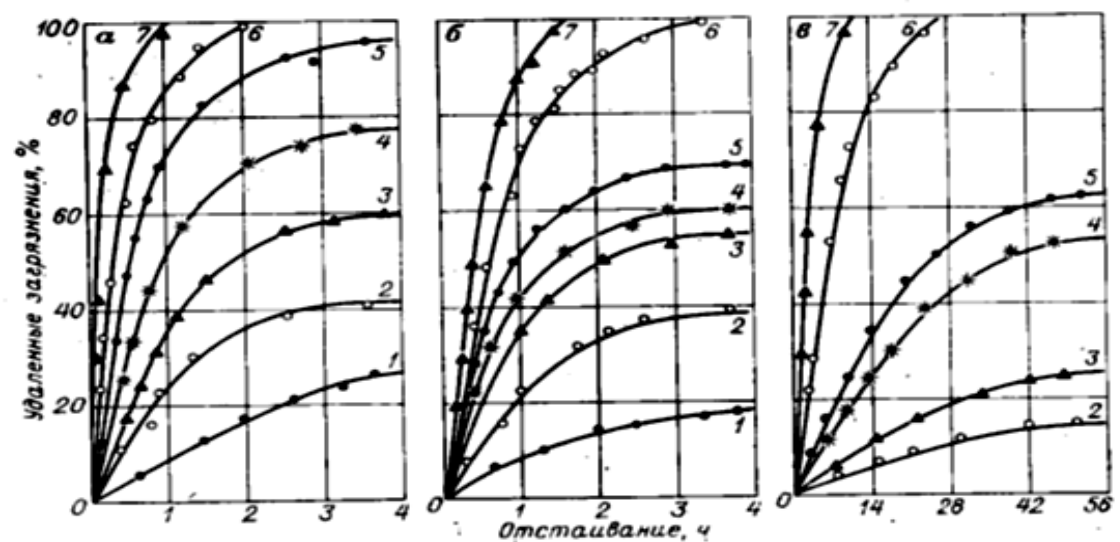

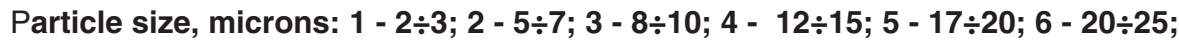

$$
7-30 \div 40
$$

Fig. 6. Velocity of settling particle contamination at $20^{\circ} \mathrm{C}$ in gasoline A-72 (a),

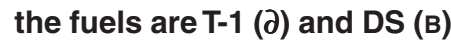

Table 5: Deposition of particles of mechanical impurities from the oil at $80{ }^{\circ} \mathrm{C}$

\begin{tabular}{lccccc}
\hline $\begin{array}{l}\text { Distance from } \\
\text { bottom, } \mathrm{mm}\end{array}$ & \multicolumn{5}{c}{ Impurity content (\%) depending on the duration of sedimentation, $\mathrm{h}$} \\
\hline 240 & 1 & 3 & 6 & 12 & 18 \\
180 & 0,14 & 0,09 & 0,03 & 0 & 0 \\
120 & 0,15 & 0,11 & 0,07 & 0 & 0 \\
60 & 0,18 & 0,16 & 0,11 & 0,03 & 0 \\
1 & 0,19 & 0,23 & 0,23 & 0,19 & 0 \\
& 0,21 & 0,33 & 0,5 & 0,75 & 0,92 \\
\hline
\end{tabular}

Table 4: Sedimentation efficiency of fuels for $20 \mathrm{~h}$ at an average temperature of $12^{\circ} \mathrm{C}$

\begin{tabular}{lcc}
\hline Indicators & Fuel F-1 & Fuel DS \\
Dirt content, g/t & $2,8 / 1,2$ & $4,3 / 1,7$ \\
\hline
\end{tabular}

The number of particles(pieces $/ \mathrm{ml})$ with dispersion, $\mu \mathrm{m}$ :

\begin{tabular}{lcc}
$1-5$ & $10370 / 9080$ & 18 830/15 685 \\
$5-10$ & $4500 / 2370$ & $11330 / 8420$ \\
$10-15$ & $1820 / 720$ & $4200 / 1030$ \\
$15-20$ & $1072 / 430$ & $1200 / 586$ \\
$20-25$ & $845 / 140$ & $938 / 242$ \\
$25-30$ & $428 / 35$ & $630 / 135$ \\
$30-40$ & $235 / 7$ & $245 / 30$ \\
$40-50$ & $140 /-$ & $180 / 6$ \\
$50-60$ & $75 /-$ & $120 /-$ \\
\hline
\end{tabular}

Note. The numerator - to defend; Denominator after settling. 


\section{CONCLUSION}

Most effectively water is removed from the fuels by settlers poppet type. With the decrease the viscosity of fuel the efficiency of sedimentation of water increases. The decrease in performance of the clarifier increases the efficiency of settling. Remove the water in the heavy viscous fuels with disc clarifiers effectively fails. Difficult to remove fine-dispersed water from fuels and oils.

Removal the water from fuel oil, especially after the transportation by water in which they additionally flood, represents at present a difficult technical problem.
Because of the small differences in the densities of water and oil and due to its high viscosity water settles very slowly and not completely. In fuel oils with a density greater than water may accumulate in the upper layer. To increase the efficiency of settling, the oil fuel and lubricating oil is heated in a special tank with heaters.

The results presented in this article was obtained in the framework of implementation of the project of the Ministry of Education and Science of the Republic of Kazakhstan No0993/ГФ4 «Polyfunctional adsorbents obtainment technology development for oil, oil products, sewage characteristics quality increasing».

\section{REFERENCES}

1. Gelperin, N. I. Basic processes and apparatuses of chemical technology. Moscow. 2011, 412.

2. Greg, S.; Sing, K. Adsorption, surface, porocity. Moscow. 2010, 407.

3. Kasatkin, A.G. Basic processes and apparatuses of chemical technology. Moscow. 2003, 752.

4. Syrmanova, K.K.; Kaldybekova, Zh.; Sakibaeva, S.; Brener, A. Expanded Vermiculite Based Adsorbent. Journal of Materials Science and Engineering. 2012, 2, 313-316.

5. Kalyanov, N.N. Vermiculite, its properties, technology and application. Perlite and Vermiculite. 2004, 110-123.

6. Iskritski, N.A. Economics and perspectives of vermiculite using. Science Leningrad Addition. 2005, 152

7. Syrmanova, K.K.; Kaldybekova, Zh. B.; Botabayev N.Y. Improving the running abilities of oil products by adsorptive method. Proceedings of international scientific research conference "Actual problems of Modern natural Sciences", Aktobe. 2016, 331-334.

8. Bolshakov, G.F. Recovery and quality control of petroleum products. 1982, 350 .

9. Syrmanova, K.K.; Kaldybekova Zh. B. Polyfunctional sorbents. Monograph. 2012, 168.

10. Syrmanova, K.K.; Kaldybekova, Zh.B.; Botabayev, N.Y. Issues of modern science. Collective monograph. 2016, 214. 